\title{
Effects of silencing the DUSP1 gene using lentiviral vector-mediated siRNA on the release of proinflammatory cytokines through regulation of the MAPK signaling pathway in mice with acute pancreatitis
}

\author{
BO ZHANG ${ }^{1,2^{*}}$, SHU-LIANG LI ${ }^{3 *}$, HUA-LEI XIE ${ }^{2}$, JIA-WEI FAN ${ }^{2}$, \\ CHUAN-WEI GU ${ }^{2}$, CHAO KANG ${ }^{2}$ and MU-JIAN TENG ${ }^{1}$ \\ ${ }^{1}$ Department of Hepatobiliary Surgery, Qianfoshan Hospital, Shandong University, Jinan, Shandong 250014; \\ Departments of ${ }^{2}$ Emergency and ${ }^{3}$ General Surgery, The Second People's Hospital of Liaocheng, \\ Liaocheng, Shandong 252600, P.R. China
}

Received July 19, 2017; Accepted January 10, 2018

DOI: $10.3892 /$ ijmm.2018.3429

\begin{abstract}
The present study investigated the effects of dual specificity phosphatase 1 (DUSP1) gene silencing using lentiviral vector-mediated small interfering (si)RNA on the release of proinflammatory cytokines through the regulation of the mitogen-activated protein kinase (MAPK) signaling pathway in mice with acute pancreatitis (AP). Two siRNA-DUSP1 sequences and one scramble siRNA sequence were designed, and the expression of DUSP1 was detected using western blot analysis to screen for the one with a higher interference rate. An AP mouse model was established, and KM mice were assigned to either a control, siRNA, AP, AP+PD98059, AP+scramble, AP+siRNA or AP+PD98059+siRNA group. The expression of proinflammatory cytokines, including tumor necrosis factor (TNF)- $\alpha$, interleukin (IL)- $1 \beta$ and IL-6, high mobility group box 1 (HMGB1), and S100A12 in serum samples were detected using an enzyme-linked immunosorbent assay at 12, 24 and $48 \mathrm{~h}$ post-modeling. The serum amylase levels were also detected. The expression levels of DUSP1, TNF- $\alpha$, IL-1 $\beta$, IL-6, HMGB1, S100A12, phosphorylated (p-) extracellular signal-regulated kinase (ERK), p-c-Jun $\mathrm{N}$-terminal kinase (JNK), p-p38, ERK, JNK and p38 in pancreatic, liver, kidney and lung tissues were detected using
\end{abstract}

Correspondence to: Dr Mu-Jian Teng, Department of Hepatobiliary Surgery, Qianfoshan Hospital, Shandong University, 16766 Jingshi Road, Jinan, Shandong 250014, P.R. China

E-mail: tmujian@126.com

*Contributed equally

Key words: lentiviral vectors, dual specificity phosphatase 1, mitogen-activated protein kinase signaling pathway, acute pancreatitis, proinflammatory cytokines, high mobility group box 1 , S100A12 reverse transcription-quantitative polymerase chain reaction and western blot analysis. Compared with the control group, the siRNA group demonstrated marginally upregulated serum amylase, lipase, urinary trypsinogen-2, and proinflammatory cytokines, HMGB1 and S100A12 in serum and tissues, with no statistically significant difference, elevated expression levels of p-ERK, p-JNK and p-p38, and decreased expression of DUSP1. The other five groups demonstrated increased expression levels of TNF- $\alpha$, IL-1 $\beta$, IL-6, HMGB1, S100A12, amylase, lipase and urinary trypsinogen-2 in serum, and increased expression levels of DUSP1, TNF- $\alpha$, IL-1 $\beta$, IL-6, HMGB1, S100A12, p-ERK, p-JNK and p-p38 in tissues. Compared with the AP group, the AP+PD98059+siRNA group had decreased expression of DUSP1 in tissues, whereas the AP+PD98059 group had decreased serum expression levels of TNF- $\alpha$, IL-1 $\beta$, IL-6, HMGB1, S100A12 and amylase, lipase and urinary trypsinogen- 2 . The expression levels of TNF- $\alpha$, IL-1 $\beta$, IL-6, HMGB1, S100A12, p-ERK, p-JNK, p-p38 in tissues, and edema of pancreatic tissue were alleviated, whereas the opposite results were observed in the AP+siRNA group with the decreased expression of DUSP1. The results suggested that DUSP1 gene silencing promoted the release of proinflammatory cytokines through activation of the MAPK signaling pathway in mice with AP.

\section{Introduction}

Acute pancreatitis (AP) is an acute inflammatory disease, which is manifested predominantly as acinar cell injury, oxidative stress and pancreatic inflammation. AP is frequently caused by gallstone disease or excess alcohol ingestion and is the primary contributor to morbidity and mortality rates worldwide $(1,2)$. The incidence of AP varies at 5-80 per 100,000 individuals throughout the world (3). AP in the majority of patients is in a mild form, however, $20 \%$ of patients develop a complicated life-threatening disease, which requires intensive and prolonged therapeutic intervention, and has a risk of organ failure and carries a mortality rate of $7-15 \%$ (4). The treatment 
of mild AP is supportive, however, severe AP characterized by pancreatic necrosis may require surgery (5). Laparotomy and debridement of the infected necrotic tissues have been reported to be the gold standard treatment in previous decades (6). However, the mortality rate of surgical intervention exceeds $50 \%$ (7). Therefore, there is an urgent requirement to identify novel diagnostic and therapeutic targets to improve the survival rate of patients with AP.

Dual-specificity phosphatase-1 (DUSP1), also known as mitogen-activated protein kinase (MAPK) phosphatase 1 , is a member of the MAPK phosphatase family and a potent negative regulator of MAPK activity, with an increasingly recognized role in tumor biology $(8,9)$. DUSP1 is overexpressed in pancreatic cancer cells in pancreatic ductal adenocarcinoma, where it increases colony formation and promotes tumorigenicity (10). The DUSP1 gene is considered a tumor suppressor and a regulator of cancer-associated inflammation (11). DUSP1 is also important in anti-inflammation effects (12). MAPKs are considered evolutionarily well-conserved serine and threonine protein enzymes, which are involved in signal transduction pathways linking cell surface receptors with main regulative nuclear and intracellular targets (13). In mammals, there are several MAPK enzymes responsible for cell proliferation, apoptosis, differentiation and survival (14). MAPK phosphatases, including DUSP1, inhibit signal transduction and cytokine activation via MAPK dephosphorylation or interference with effector molecules binding to MAPKs, including extracellular signal-regulated kinase (ERK) (15). MAPKs are considered to be main signal transducers in the early stage of the development of AP (16). Lentiviral vectors enable the maintenance of the sustained long-term expression of transgenes in various mammalian cells with a substantial packaging capacity and extensive cell tropism, and their development produces a system, which can be applied to decrease the expression of target genes $(17,18)$. The proinflammatory cytokines, including tumor necrosis factor- $\alpha(\mathrm{TNF}-\alpha)$ and interleukin-6 (IL-6), not only promote inflammation but also have an effect on the generation and duration of inflammatory pain by acting on sensory nerve cells (19). Based on these findings, it was hypothesized that there may be an effect of silencing the DUSP1 gene by lentiviral vector-mediated small interfering siRNA on the release of proinflammatory cytokines through regulation of the MAPK signaling pathway in mice with AP.

\section{Materials and methods}

Construction and detection of the psiRNA-DUSP1 vector. Two DUSP1-siRNAs and one negative control (NC) sequence were designed according to the mouse DUSP1 gene sequence in the gene bank as follows: siRNA1: 5'-TAGCGTCAA GACATTTGCTGA-3'; siRNA2: 5'-CTGTACTATCCTGTA AATATA-3'; and negative: 5'-AACTGGACTTCCAGA AGAACA-3'. The siRNA and NC sequences were synthesized by Shanghai Sangon Biological Technology Co., Ltd. (Shanghai, China). According to the synthesized siRNA and NC sequences, restriction sites BamHI and EcoRI were added to both ends to synthesize oligo DNA for forming double-stranded DNA post-annealing. Subsequently, the DNA was inserted into a linear plasmid $\mathrm{pSIH}_{1}-\mathrm{H}_{1}-\mathrm{copGFP}$, which was enzyme-digested by $B a m \mathrm{HI}$ and EcoRI through the $\mathrm{T}_{4}$ DNA ligase and was transformed into DH5 $\alpha$ competent cells (CB10; Tiangen Biotech Co., Ltd., Beijing, China). Subsequently, plasmids were extracted and transfected with FuGENE6 (Roche Diagnostics, Indianapolis, IN, USA) according to the manufacturers protocol. There were four groups in the transfection experiments: Blank group (transfected with empty plasmid pSIH), NC group (transfected with pSIH-NC plasmid), siRNA1 group (transfected with pSIH-DUSP1-siRNA1 plasmid), and siRNA2 group (transfected with pSIH-DUSP1-siRNA2 plasmid). Following transfection for $48 \mathrm{~h}$, the expression of DUSP1 in each group was detected using western blot analysis, as in the subsequent animal experiment), and the silencing efficiency of siRNA was determined using Gel-Pro Analyzer software (version 4.0; Media Cybernetics, Inc., Rockville, MD, USA).

Lentivirus packaging and titer determination. The pSIH-DUSP1-siRNA and pSIH-NC with high silencing efficiency were selected to co-transfect 293T cells (purchased from the Shanghai Institute of Cell Biology, Chinese Academy of Sciences, Shanghai, China) with a packaging plasmid mixture respectively using the lipofection method. The cells were divided into three groups: Control group (cells infected with empty plasmid lentivirus), scramble group (cells infected with NC lentivirus), and siRNA group (cells infected with siRNA lentivirus). The method was as follows: $12 \mathrm{~h}$ prior to transfection, the 293T were cells seeded on a 6-well plate at $5 \times 10^{5}$ cells/well using Dulbecco's modified Eagle's Medium (DMEM; Corning Incorporated, Corning, NY, USA) with 5\% fetal bovine serum (FBS; cat. no. 10100-147; Thermo Fisher Scientific, Inc., Waltham, MA, USA) as the culture medium. The liposome Lipofectamine 2000 (20 $\mu \mathrm{l})$ was added to $500 \mu 1$ of DMEM without serum and double antibody followed by even mixing. To the corresponding $2 \mathrm{ml}$ centrifuge tubes, $2 \mu \mathrm{g}$ of pSIH-DUSP1-siRNA, pSIH-NC, or empty plasmid and $10 \mu \mathrm{g}$ of lentivirus packaging plasmid was added, followed by mixing and incubating for $5 \mathrm{~min}$ at $37^{\circ} \mathrm{C}$. The corresponding centrifuge tubes were mixed and stood for $20 \mathrm{~min}$, and then moved onto the 293T cell culture plate. After $6 \mathrm{~h}$, the culture medium was replaced. After $72 \mathrm{~h}$, the supernatant of the virus was collected for viral titer determination. The 293T cells were incubated in a 96-well plate with $2 \times 10^{8}$ cells $/ \mathrm{ml}$, and each well received $100 \mu 1$ DMEM containing $10 \%$ FBS overnight. In the viral titer determination test, eight wells were assigned to each group, with the first containing $10 \mu \mathrm{l}$ of the virus to be tested. The remaining wells were diluted at 10:1, with the final well serving as a blank control. After $48 \mathrm{~h}$, the number of green fluorescent cells was observed under a fluorescence inverted microscope from a high concentration to a low concentration. If the number of positive cells in the first well was more than five, and the fluorescence disappeared subsequent to this well, or if the fluorescence disappeared in the later wells, and the number of positive cells in this well was less than five, then the well was considered to be metering well and recorded as $1 \mathrm{IU}$. The number of positive cells was recorded as ' $\mathrm{m}$ ', and the viral titer was calculated as follows: Viral titer $=\mathrm{m} \times(1 \mathrm{IU} \times$ dilution rate of metering well relative to the first well)/volume of virus added to the first well (20). 
Preparation and grouping of the AP mouse model. A total of 105 male KM mice in healthy condition (4-6 weeks old) with a weight range of $20 \pm 2 \mathrm{~g}$ at clean grade were used. The animals were maintained at $50-60 \%$ humidity, $22-24^{\circ} \mathrm{C}$ and a $12 \mathrm{~h}$ day/night cycle. Animals were provided by the Experimental animal Center of Sichuan University (Sichuan, China). Prior to the experiment, the mice used for the AP model were fasted for $12 \mathrm{~h}$ for gastrointestinal decompression in order to prevent the overproduction of pancreatic juice; however, they all had free access to water. The mice were intraperitoneally injected twice with a $1 \mathrm{~h}$ interval with $20 \%$ L-arginine (cat. no. L101021; Sigma-Aldrich; Merck Millipore, Darmstadt, Germany) at $4 \mathrm{~g} / \mathrm{kg}$ to establish the AP mouse model. Using a Table of random numbers, the mice were divided into seven groups with 15 mice in each group: Control group (mice injected with the same dose of normal saline); siRNA group (mice injected with $0.88 \mathrm{mg} / \mathrm{kg}$ DUSP1-siRNA lentivirus); AP group (AP mouse model); AP+PD98059 group [0.5 $\mathrm{h}$ pre-induction and $1 \mathrm{~h}$ post-induction, the mice were intraperitoneally injected with PD98059 at $10 \mathrm{mg} / \mathrm{kg}$ (cat. no. HY-12028; MedChem Express; Monmouth Junction, NJ, USA); AP+siRNA group (following successful model establishment, lentiviruses containing $0.88 \mathrm{mg} / \mathrm{kg}$ DUSP1-siRNA were injected into mice intraperitoneally); AP+scramble group (following successful model establishment, $0.88 \mathrm{mg} / \mathrm{kg}$ scramble-siRNA lentiviral vectors were injected intraperitoneally); AP+PD98059+siRNA group ( $0.5 \mathrm{~h}$ pre-induction and $1 \mathrm{~h}$ post-induction, mice were intraperitoneally injected with PD98059 at $10 \mathrm{mg} / \mathrm{kg}$, and following successful model establishment, lentiviruses containing $0.88 \mathrm{mg} / \mathrm{kg}$ DUSP1-siRNA were injected into mice intraperitoneally). The mice in each group received cardiac blood sampling (as blood specimen) at 12, 24 and $48 \mathrm{~h}$ post-modeling, respectively. After $48 \mathrm{~h}$, the mice were sacrificed and pancreatic tissue, liver tissue, lung tissue and kidney tissue were immediately obtained. The present study was approved by the experimental animal ethics committee of Qianfoshan Hospital, Shandong University (Shandong, China), in accordance with the principles of animal protection, animal welfare and ethics, and in line with the relevant provisions of national experimental animal welfare ethics.

Hematoxylin and eosin (HE) staining. The pancreatic, liver, kidney and lung tissues of mice in each group were removed and fixed with $4 \%$ formaldehyde for $6 \mathrm{~h}$, and immersed and embedded in paraffin. The paraffin-embedded pancreatic tissues were cut into $3-\mu \mathrm{m}$ sections, which were heated at $60^{\circ} \mathrm{C}$ overnight. The sections were dewaxed in xylene I and xylene II for $20 \mathrm{~min}$ each, soaked in 100, 95, 80 and $70 \%$ ethanol for $5 \mathrm{~min}$ each, and then washed with distilled water. The sections were dyed with hematoxylin staining for $10 \mathrm{~min}$ and rinsed with tap water for 15 min until black-blue, followed by eosin staining for $30 \mathrm{sec}$, and washing with double distilled water for flushing red. The sections were then dehydrated in ethanol, cleaned in xylene and mounted by neutral gum. Histopathological examination of the HE staining was performed using light microscopy (BX53; Olympus, Tokyo, Japan). Using the morphological image analysis system (I-Solutiontype; IMT i-solution Inc., Vancouver, BC, Canada), images of the HE-stained sections of pancreatic, liver, kidney and lung tissues in each group were captured at x400 magnification. The experiment was repeated three times.

Enzyme-linked immunosorbent assay (ELISA). At 12, 24 and $48 \mathrm{~h}$ post-model establishment, five mice in each group were selected for cardiac blood sampling. The blood was reserved at room temperature for $30 \mathrm{~min}$ and then centrifuged at $1,960 \mathrm{x} \mathrm{g}$ $\left(4^{\circ} \mathrm{C}\right)$ for $15 \mathrm{~min}$ for separation of the serum. Experimental procedures were performed in strict accordance with the instructions of the TNF- $\alpha$ ELISA kit (cat. no. ab208348; Abcam, Cambridge, MA, USA), IL-1 $\beta$ ELISA kit (cat. no. ab100704; Abcam), IL-6 ELISA kit (cat. no. ab100713; Abcam), HMGB1 ELISA kit (cat. no. E0399m; Beijing Huaxia Ocean Technology Co., Ltd., Beijing, China) and S100A12 ELISA kit (cat. no. hz-EL-M1036c; Shanghai Huzhen Biological Technology Co., Ltd., Shanghai, China). The ELISA kits were stood at room temperature for $20 \mathrm{~min}$ and washing solution was prepared. Following dissolution, $100 \mu \mathrm{l}$ standard was added into the reaction plate to construct a standard curve. A total of $100 \mu \mathrm{l}$ of each sample was added to the reaction plate for incubation at $37^{\circ} \mathrm{C}$ for $90 \mathrm{~min}$, and the plate was washed five times at intervals of $30 \mathrm{sec}$. Following washing, $100 \mu \mathrm{l}$ of biotinylated antibody working fluid was added for incubation at $37^{\circ} \mathrm{C}$ for $60 \mathrm{~min}$, and the plate was washed five times at intervals of $30 \mathrm{sec}$. Subsequently, $100 \mu \mathrm{l}$ of the enzyme binding agent (light-avoiding) working fluid was added for incubation at $37^{\circ} \mathrm{C}$ for $30 \mathrm{~min}$, and the plate was washed five times. Finally, stop buffer was added to terminate the reaction and the universal microplate reader (BioTek Synergy 2; BioTek Instruments, Inc., Winooski, VT, USA) was used to measure the optical density (OD) value of each well at $450 \mathrm{~nm}$ within $3 \mathrm{~min}$. The standard curve was drawn and expression levels of the proinflammatory factors (TNF- $\alpha$, IL- $1 \beta$, IL- 6 and HMGB1) and S100A12 were measured according to the OD value.

Determination of serum amylase, lipase and urinary trypsinogen-2 levels. The levels of amylase, lipase and urinary trypsinogen-2 in serum were determined at 12, 24 and $48 \mathrm{~h}$ post-model establishment in each group. An Olympus Au2700 system (Olympus) was used to determine serum amylase levels. The lipase was detected using a Roche modular P800 automatic biochemical analyzer and its reagents (Roche Diagnostics $\mathrm{GmbH}$, Mannheim, Germany). Urine trypsinogen-2 was detected by ELISA with a Johnson Bitros-350 automatic chemical analyzer (Johnson \& Johnson, New Brunswick, NJ, USA); the kits were purchased from Shanghai Westang Bio-tech Co., Ltd. (Shanghai, China).

Reverse transcription-quantitative polymerase chain reaction (RT-qPCR) analysis. Based on the manufacturer's protocol of the TRIzol kit (Invitrogen; Thermo Fisher Scientific, Inc.), total RNA from the tissue specimens was extracted via the TRIzol one-step method. RNA was dissolved in ultrapure water, which was treated with diethylpyrocarbonate (Shanghai Sangon Biological Technology Co., Ltd., Shanghai, China). The ND-1000 UV/visible spectrophotometer (Thermo Fisher Scientific, Inc.) was used to measure OD values at 260 and $280 \mathrm{~nm}$, and the quality and concentration of total RNA were identified and determined. The reverse 
Table I. Primer sequences for reverse transcription-quantitative polymerase chain reaction analysis.

\begin{tabular}{ll}
\hline Factor & \multicolumn{1}{c}{ Primer sequence } \\
\hline TNF- $\alpha$ & F: 5'-TGATCCGCGACGTGGAA-3' \\
& R: 5'-ACCGCCTGGAGTTCTGGAA-3' \\
IL-1 $\beta$ & F: 5'-CTCCATGAGCTTTGTACAAGG-3' \\
& R: 5'-TGCTGATGTACCAGTTGGGG-3' \\
IL-6 & F: 5'-CCAGAGATACAAAGAAATGATGG-3' \\
& R: 5'-ACTCCAGAAGACCAGAGGAAAT-3' \\
DUSP1 & F: 5'-AACAGGGCAGAAGAGAAAGG-3' \\
& R: 5'-TCATCGGGAATGGTTAATACTG-3' \\
HMGB1 & F: 5'-CTCAGAGAGGTGGAAGACCATGT-3' \\
& R: 5'-GGGATGTAGGTTTTCATTTCTCTTTC-3' \\
S100A12 & F: 5'-CCATGCCCTCTACAAGAATGA-3' \\
& R: 5'-TATCACCATCGCAAGGAACTC-3' \\
$\beta$-actin & F: 5'-GCACCACACCTTCTACAATG-3' \\
& R: 5'-TGCTTGCTGATCCACATCTG-3'
\end{tabular}

TNF- $\alpha$, tumor necrosis factor- $\alpha$; IL, interleukin; DUSP1, dual specificity phosphatase 1 ; HMGB1, high mobility group box-1; F, forward; R, reverse.

transcription of the extracted RNA was performed in two steps according to the protocol of the kits (cat. no. RR037Q; Takara Biotechnology, Co., Ltd., Dalian, China). The reverse transcription system comprised $2 \mu \mathrm{l}$ of $5 \mathrm{X}$ PrimeScript buffer (for real-time), $0.5 \mu \mathrm{l}$ of PrimeScript RT enzyme mix I, $0.5 \mu \mathrm{l}$ of Oligo dT primer $(50 \mu \mathrm{m}), 0.5 \mu \mathrm{l}$ of random primers $(100 \mu \mathrm{m})$ and $2 \mu \mathrm{g}$ of total RNA, and RNase-free $\mathrm{dH}_{2} \mathrm{O}$ was added to make the sample up to $20 \mu \mathrm{l}$. The reaction conditions were as follows: $37^{\circ} \mathrm{C}$ for $15 \mathrm{~min}, 85^{\circ} \mathrm{C}$ for $5 \mathrm{sec}$ and $4^{\circ} \mathrm{C}$ for $5 \mathrm{~min}$. The cDNA obtained by reverse transcription was stored temporarily for further use in a refrigerator at $-80^{\circ} \mathrm{C}$. The RT-qPCR was performed using the TaqMan probe method according to the kit protocol (Fermentas; Thermo Fisher Scientific, Inc.). The primer sequences are presented in Table I. The reaction conditions were as follows: Pre-denaturation at $95^{\circ} \mathrm{C}$ for $30 \mathrm{sec}$; denaturation at $95^{\circ} \mathrm{C}$ for $10 \mathrm{sec}$, annealing at $60^{\circ} \mathrm{C}$ for $20 \mathrm{sec}$, and extension at $70^{\circ} \mathrm{C}$ for $10 \mathrm{sec}$, repeated for 40 cycles. The reaction system was as follows: Premix Ex Taq or SYBR-Green mix (12.5 $\mu \mathrm{l})$, forward primer $(1 \mu \mathrm{l})$, reverse primer $(1 \mu \mathrm{l})$, cDNA $(1-4 \mu \mathrm{l}), \mathrm{ddH}_{2} \mathrm{O}$ up to $25 \mu \mathrm{l}$. The RT-qPCR platform (Bio-Rad iQ5; Bio-Rad Laboratories, Inc., Hercules, CA, USA) was used for detection. With $\beta$-actin as an internal reference, the relative expression of each target gene was calculated using the $2^{-\Delta \Delta \mathrm{Cq}}$ method (21). The experiment was repeated three times and the mean value was obtained.

Western blot analysis. Pancreatic, liver, kidney and lung tissue samples $(0.3 \mathrm{~g}$ each) were extracted and cut into $0.5 \times 0.5 \times 0.5 \mathrm{~mm}$ sections on ice with ophthalmic scissors following removal of blood and other tissues with pre-cold 1X PBS solution. The prepared 3-ml lysate [7 mol/1 urea, $2 \mathrm{~mol} / \mathrm{l}$ thiourea, $5 \mathrm{ml} / \mathrm{l} \mathrm{IPG}$ buffer (pH 3-10), $65 \mathrm{mmol} / \mathrm{l} \mathrm{DTT}$,
$40 \mathrm{~g} / \mathrm{l} \mathrm{CHAPS}$ and $5 \mathrm{mg} / \mathrm{l}$ protease inhibitor] was added to the sections and mixed, and the mixture was shattered on ice using ultrasound. Subsequently, the sections were centrifuged at $12,000 \mathrm{~g}$ at $4^{\circ} \mathrm{C}$ for $30 \mathrm{~min}$, and the supernatant was used as protein extracts. The bicinchoninic acid method was used to determine the protein concentration. Subsequently, 5X SDS lysate (cat. no. P0013G; Beyotime Institute of Biotechnology, Beijing, China) was added to inactivate proteins at $100^{\circ} \mathrm{C}$ for $5 \mathrm{~min}$. A loading sample (40 $\mu \mathrm{g})$ was extracted for electrophoresis on a polyacrylamide gel (5\% concentrated gel and $12 \%$ separating gel). Following transfer onto a nitrocellulose transmembrane, the membrane was sealed in TBS-T containing $5 \%$ bovine serum albumin (BSA) (Guangzhou Tiancheng Medical Technology Co., Ltd., Guangzhou, China) at room temperature for $1 \mathrm{~h}$. The sealing liquid was discarded and the membrane was placed in the plastic groove. Subsequently, the membranes were incubated with the corresponding concentration of primary rabbit anti-DUSP1 (cat. no. ab178883; Abcam; 1:1,000), rabbit anti-ERK (cat. no. ab212206; Abcam; 1:1,000), rabbit anti-p-ERK (cat. no. ab214362; Abcam; 1:1,000), rabbit anti- c-Jun N-terminal kinase (JNK; cat. no. ab199380; Abcam; 1:2,500), rabbit anti-p-JNK (cat. no. ab76572; Abcam; 1:5,000), rabbit anti-p38 (cat. no. ab32142; Abcam; 1:1,000), anti-p-p38 (cat. no. ab47363; Abcam; 1:1,000) and rabbit anti- $\beta$-actin (cat. no. ab5694; Abcam 1:10,000). All the above antibodies were prepared in 5\% BSA. The transfer surface was upward and the membranes were placed in a refrigerator at $4^{\circ} \mathrm{C}$ overnight. The following day, TBST was used to rinse the membranes three times (10 min per rinse). The diluted secondary antibody (goat anti-rabbit; cat. no. ab6721; Abcam) was added for incubation at $4^{\circ} \mathrm{C}$ for $4-6 \mathrm{~h}$, and the membranes were washed in TBST three times for 15 min each. The chemiluminescence reagent A and B solutions (Yan Hui Biological Co., Ltd., Shanghai, China; 1:1) were mixed and evenly dripped on the membrane, and developer solution was used for development. All bands were subjected to relative OD analysis. The experiment was repeated three times with the mean value calculated.

Statistical analysis. SPSS 21.0 statistical software (IBM SPSS, Armonk, NY, USA) was used to process the data. The measurement data are presented as the mean \pm standard deviation. The comparisons among multiple groups were performed using one-way analysis of variance, followed by Fisher's least significant difference or Tamhane's T2 tests, and the comparisons between two groups were performed using an independent t-test. $\mathrm{P}<0.05$ was considered to indicate a statistically significant difference.

\section{Results}

siRNA2 presents with higher silencing efficiency. The results of western blot analysis (Fig. 1) demonstrated that, compared with the blank group, no significant difference was identified in the expression of DUSP1 in the NC group ( $\mathrm{P}>0.05)$. Compared with the blank group, the expression of DUSP1 in the siRNA1 group was decreased $(35.56 \%)$ and in the siRNA2 group was decreased $(54.72 \%)$, which indicated that the silencing efficiency of siRNA2 was higher. Therefore, pSIH-DUSP1-siRNA2 was used to package with the lentivirus. 
A

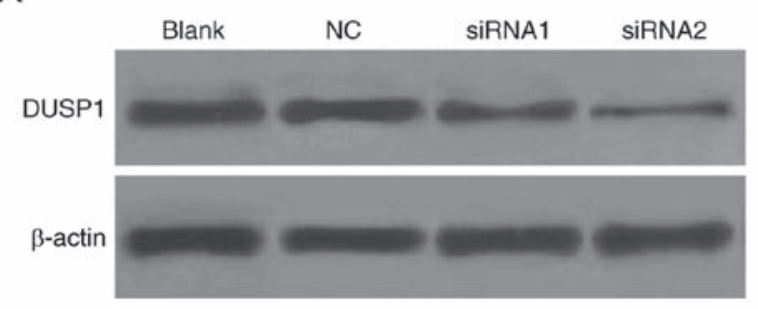

$\mathrm{B}$

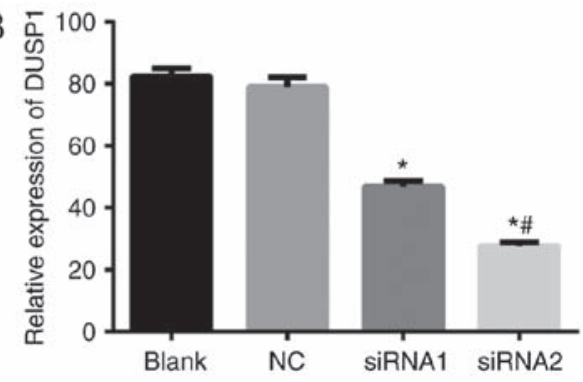

Figure 1. Expression of DUSP1 in each transfection group detected using western blot analysis. (A) Band chart of the expression of DUSP1 in each transfection group, detected using western blot analysis. (B) Histogram of the expression of DUSP1 in each transfection group, detected using western blot analysis. ${ }^{*} \mathrm{P}<0.05$, compared with the blank and NC groups; ${ }^{\#} \mathrm{P}<0.05$, compared with the siRNA1 group. DUSP1, dual-specificity phosphatase-1; NC, negative control; siRNA, small interfering RNA.

Titer determination of lentivirus and results of 293 T cell infection. The titer of the lentivirus concentrate was $5.62 \times 10^{8} \mathrm{TU} / \mathrm{ml}$ following serial dilution, and the virus was successfully packaged. Under fluorescence microscopy, cells that produced green fluorescence were infected successfully. There were no fluorescent cells in the control group. The number of green fluorescent cells in the scramble and siRNA groups accounted for $>90 \%$ of the total cells, indicating that the infection rate of the lentivirus to the scramble and siRNA groups was $>90 \%$ (Fig. 2).

Pathological changes in pancreatic, liver, kidney and lung tissues of mice in each group. The pancreatic tissues were stained using HE and observed under a light microscope (Fig. 3). In the control and siRNA groups, the acini and lobules of the pancreatic tissues were intact and the stroma was normal, with no bleeding or necrosis. In the AP+PD98059 group, there was infiltration of neutrophils and monocytes with no notable vascular lesion. In the AP, AP+scramble and AP+PD98059+siRNA groups, the stroma of the pancreas exhibited hyperemia, and edema was accompanied by obscure cell structure, inflammatory cell infiltration, vascular dilatation and congestion. The AP+siRNA group demonstrated regions of focal acinar necrosis, inflammatory cell infiltration, occasional bleeding and marginal fat necrosis.

The liver tissue was observed under light microscopy. In the control and siRNA groups, the stem cells were larger, with a polyhedral shape, large and round nuclei, and an intact nuclear membrane. The AP+PD98059 group exhibited lymphocytic infiltration in liver tissues and a loose hepatocyte cytoplasm. The AP, AP+scramble and AP+PD98059+siRNA groups exhibited impaired lung tissues and inflammatory cell infiltration. In the AP+siRNA group, the hepatic lobules were not clear, and there were numerous fat vacuoles of different sizes, spotty necrosis of hepatocytes, and marked inflammatory cell infiltration in the cytoplasm.

The kidney tissue was observed under a light microscope. In the control and siRNA groups, there were no marked changes in the kidney tissue. In the AP+PD98059 group, the glomerular endothelial cells were swollen with interstitial edema and inflammatory cell infiltration. In the AP, $\mathrm{AP}+$ scramble and AP+PD98059+siRNA groups, the cortical renal tubular epithelial cells were vacuolar and drip shaped, the brush border disappeared and there was a marked band of congestion. In the AP+siRNA group, there was marked congestion, endotheliocytic swelling, interstitial edema, and inflammatory cell infiltration in the glomerulus, and degeneration, necrosis and a disappearing cell striated border were observed in renal tubular epithelial cells.

The lung tissue was observed under light microscopy. In the control and siRNA groups, the lung tissue was structurally complete, the airway epithelial cells were arranged regularly with complete alveolar spaces, and the interstitial cells were free of edema without notable inflammatory cell infiltration, bleeding or edema fluid. The AP+PD98059 group exhibited interstitial edema and inflammatory cell infiltration. In the AP, AP+scramble and AP+PD98059+siRNA groups, inflammatory cells had infiltrated and diffused into the lung stroma. In the AP+siRNA group, there was marked inflammatory cell infiltration, evidence of alveolar structure damage, and evidence of epithelial cell denaturing and detachment.

TNF- $\alpha, I L-1 \beta, I L-6, H M G B 1$ and S100A12 are expressed at high levels in AP mice. Compared with the control group, at 12, 24 and $48 \mathrm{~h}$ post-model establishment, the expression levels of TNF- $\alpha$, IL-1 $\beta$, IL-6, HMGB1 and S100A12 in serum were increased in the siRNA group, but without statistical significance (all $\mathrm{P}>0.05$ ); however, these levels increased significantly in the other five groups $(\mathrm{P}<0.05)$. Compared with the AP group, at 12, 24 and $48 \mathrm{~h}$ post-model establishment, the AP+PD98059 group exhibited decreased expression levels of TNF- $\alpha$, IL-1 $\beta$, IL-6, HMGB1 and S100A12 in serum $(\mathrm{P}<0.05)$ and the $\mathrm{AP}+$ siRNA group had increased expression levels of TNF- $\alpha$, IL-1 $\beta$, IL-6, HMGB1 and S100A12 in serum $(\mathrm{P}<0.05)$. No significant differences were observed between the AP group and the AP+scramble and AP+PD98059+siRNA groups $(\mathrm{P}>0.05$; Table II).

Higher serum levels of amylase, lipase and urinary trypsinogen-2 are identified in AP mice. The serum levels of amylase, lipase and urinary trypsinogen-2 level of mice in the control and siRNA groups demonstrated no significant difference with time extension (12, 24 and $48 \mathrm{~h}$ ). The serum levels of amylase, lipase and urinary trypsinogen-2 of mice in the other five groups initially increased and then decreased as time was extended (12, 24 and $48 \mathrm{~h}$ ), reaching a peak at $24 \mathrm{~h}$ post-model establishment. Compared with the control group, the serum levels of amylase, lipase and urinary trypsinogen-2 of 

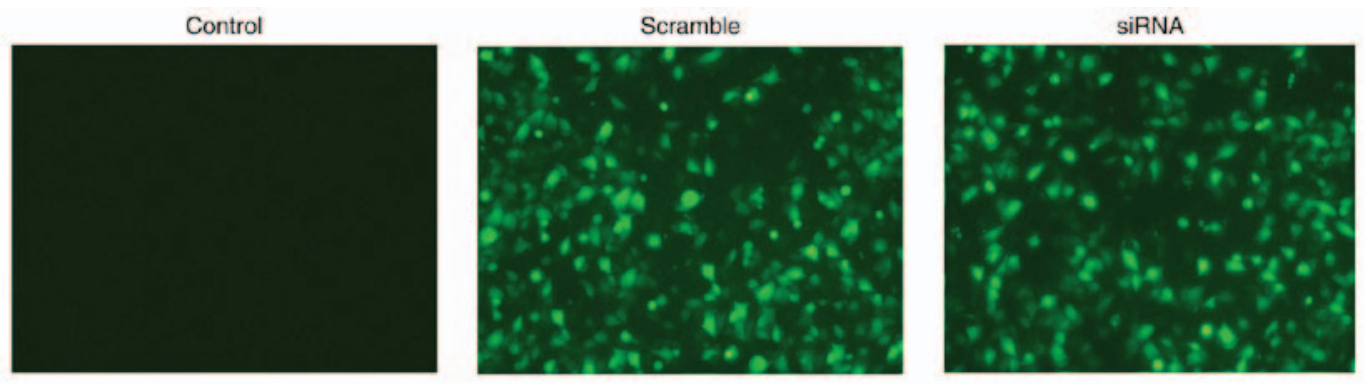

Figure 2. 293T cells under the fluorescence microscopy (magnification, $\mathrm{x} 100$ ).
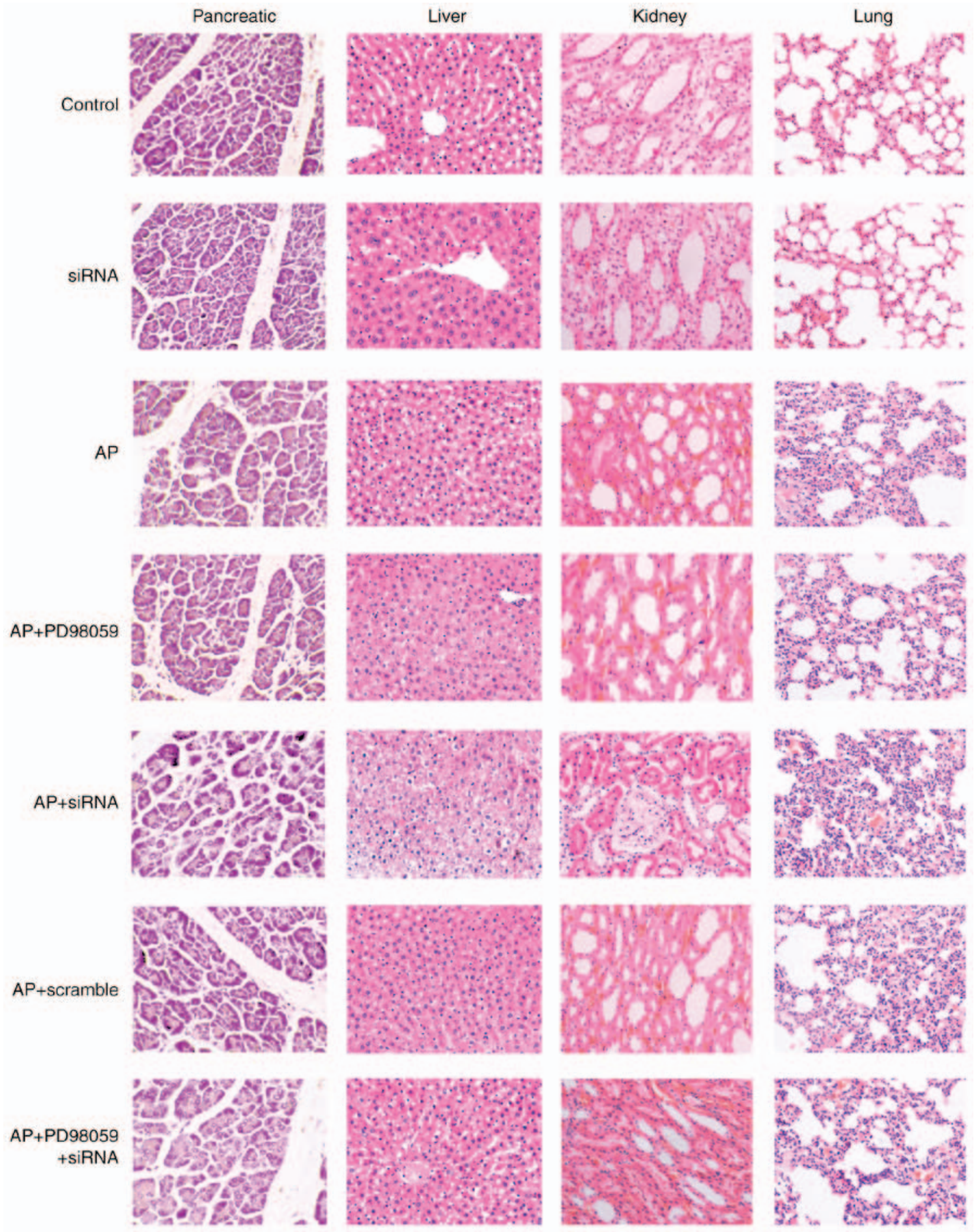

Figure 3. Results of HE staining (magnification, $\mathrm{x} 400$ ) in pancreatic, liver, kidney and lung tissues of mice in each group. HE, hematoxylin and eosin; AP, acute pancreatitis; siRNA, small interfering RNA. 


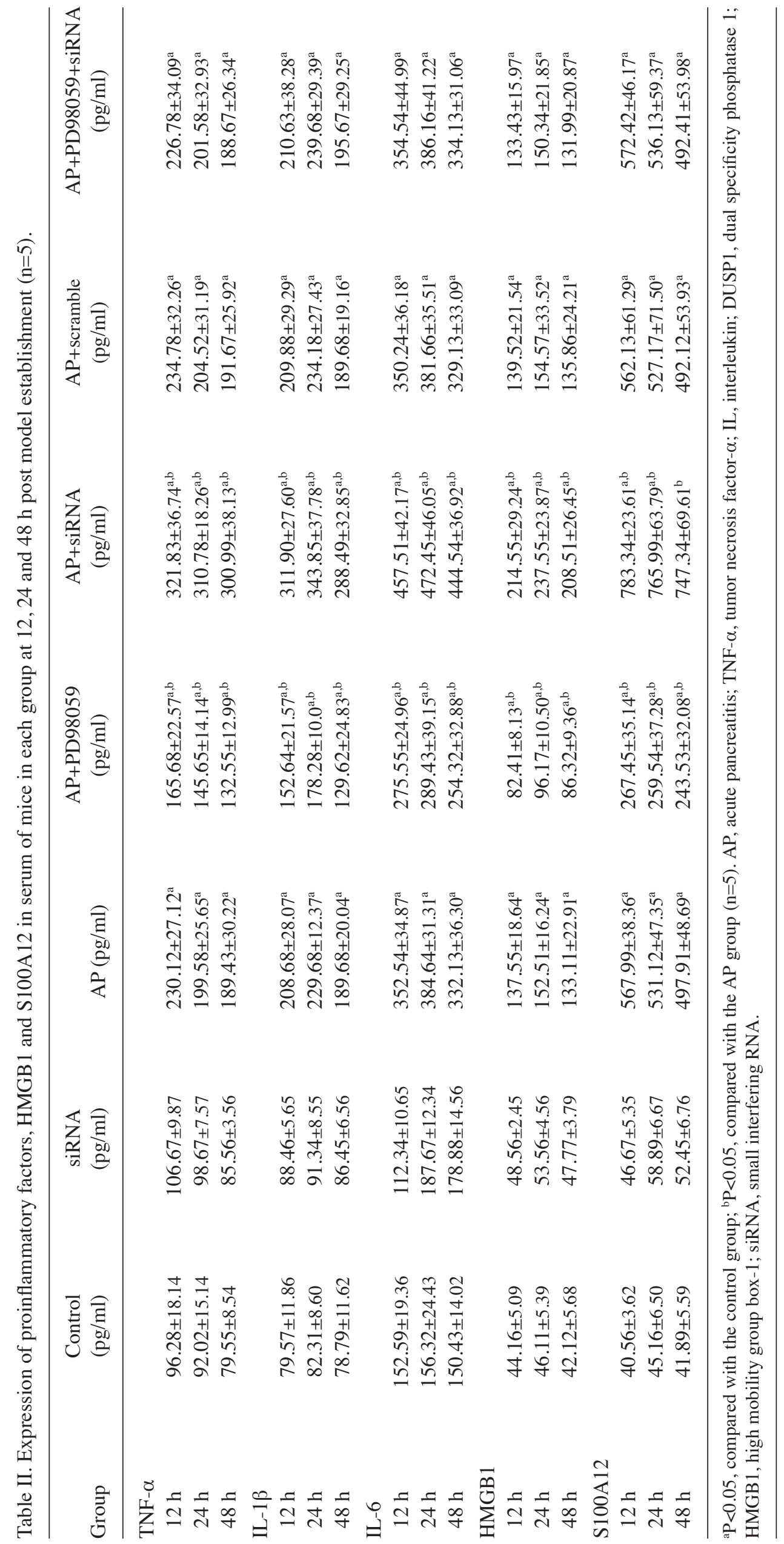


mice in the other five groups increased significantly at 12,24 and $48 \mathrm{~h}$ post-model establishment $(\mathrm{P}<0.05)$. Compared with the AP group, the AP+PD98059 group demonstrated significantly decreased serum levels of amylase, lipase and urinary trypsinogen-2 at 12, 24 and $48 \mathrm{~h}$ post-model establishment $(\mathrm{P}<0.05)$. The AP+siRNA group demonstrated significantly increased serum levels of amylase, lipase and urinary trypsinogen-2 of mice at 12, 24 and $48 \mathrm{~h}$ post-model establishment $(\mathrm{P}<0.05)$, whereas no significant differences were observed in the $\mathrm{AP}+$ scramble and $\mathrm{AP}+\mathrm{PD} 98059+$ siRNA groups $(\mathrm{P}>0.05$; Table III).

mRNA expression of TNF- $\alpha, I L-1 \beta, I L-6, D U S P 1, H M G B 1$ and S100A12 in pancreatic, liver, kidney and lung tissues of mice in each group. The result of the RT-qPCR analysis (Fig. 4A-H) demonstrated that, compared with the control group, there were no significant differences in the levels of inflammatory factors in the siRNA group (all $\mathrm{P}>0.05$ ), whereas the expression of DUSP1 was decreased. The other five groups exhibited significantly increased mRNA expression levels of TNF- $\alpha$, IL-1 $\beta$, IL-6, DUSP1, HMGB1 and S100A12 in pancreatic, liver, kidney and lung tissues, among which pancreatic tissues demonstrated the most marked increase (all $\mathrm{P}<0.05)$. Compared with the AP group, there was no significant difference in the $\mathrm{AP}+$ scramble group ( $\mathrm{P}>0.05)$, whereas the AP+PD98059 group had significantly decreased mRNA expression of TNF- $\alpha$, IL-1 $\beta$, IL-6, HMGB1 and S100A12 in pancreatic, liver, kidney and lung tissues, among which pancreatic tissues demonstrated the most marked decrease (all $\mathrm{P}<0.05$ ), however, no significant difference was identified in the mRNA expression of DUSP1. The AP+siRNA group had increased mRNA expression levels of TNF- $\alpha$, IL-1 $\beta$, IL-6, HMGB1 and S100A12 in pancreatic, liver, kidney and lung tissues, among which pancreatic tissues demonstrated the most marked increase (all $\mathrm{P}<0.05$ ), and the mRNA expression of DUSP1 was decreased. The AP+PD98059+siRNA group demonstrated no significant difference in the mRNA expression of TNF- $\alpha$, IL-1 $\beta$, IL-6, HMGB1 and S100A12 in pancreatic, liver, kidney and lung tissues ( $\mathrm{P}>0.05)$, however, the mRNA expression of DUSP1 decreased significantly $(\mathrm{P}<0.05)$.

Expression of DUSP1 and MAPK pathway-related genes (p-ERK, $p$-JNK and p-p38) in pancreatic, liver, kidney and lung tissues of mice in each group. The results of the western blot analysis (Fig. 5) demonstrated no significant differences in protein expression levels of ERK, JNK or p38 in the pancreatic, liver, kidney and lung tissues among the seven treatment groups $(\mathrm{P}>0.05)$. Compared with the control group, the expression levels of p-ERK, p-JNK and p-p38 in the pancreatic, liver, kidney and lung tissues in the other six treatment groups were significantly increased, among which the pancreatic tissue exhibited the most marked changes $(\mathrm{P}<0.05)$. The protein expression of DUSP1 was significantly decreased in the siRNA group, but increased in the other five groups (all $\mathrm{P}<0.05$ ). No statistically significant difference was observed in the AP+scramble group when compared with the AP group $(\mathrm{P}>0.05)$. Compared with the AP group, the AP+PD98059 group exhibited significantly decreased expression levels of p-ERK, p-JNK and p-p38 in the pancreatic, liver, kidney and lung tissues, among which the pancreatic tissue 
A

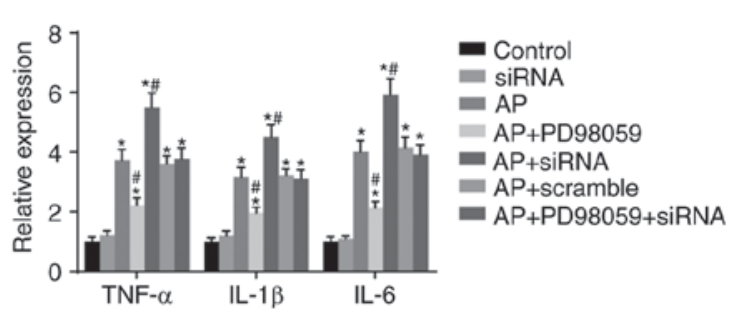

C

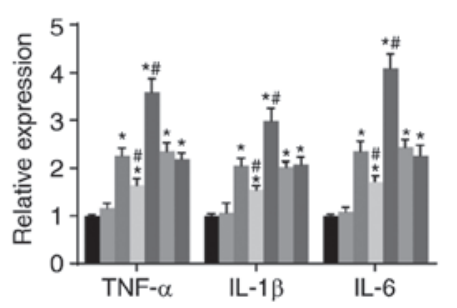

E

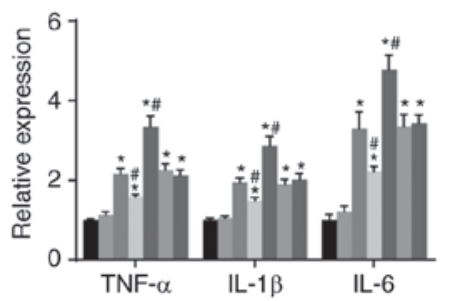

G

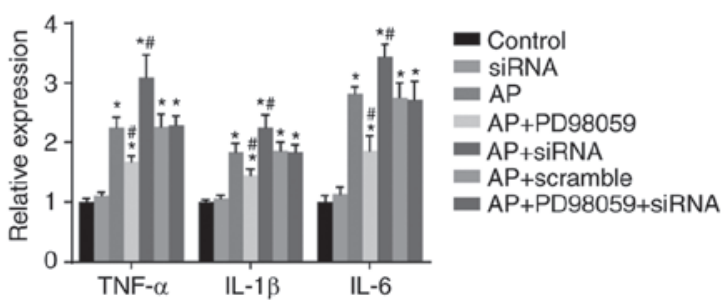

B

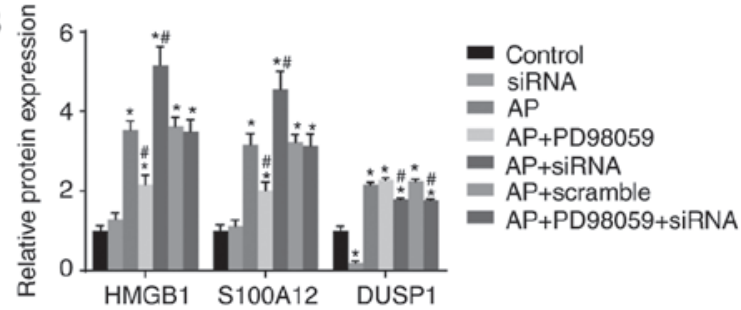

D

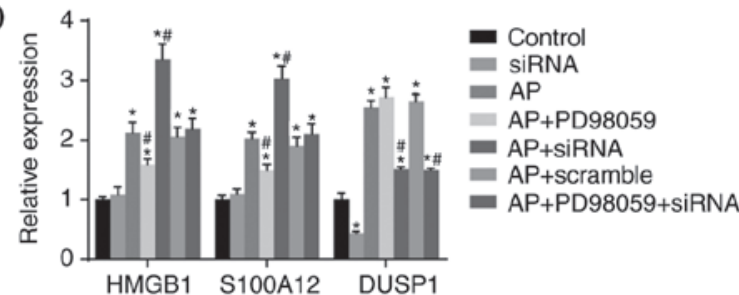

F

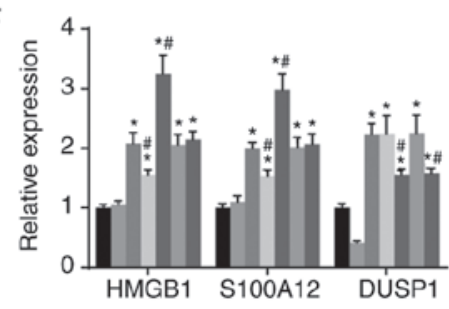

$\mathrm{H}$

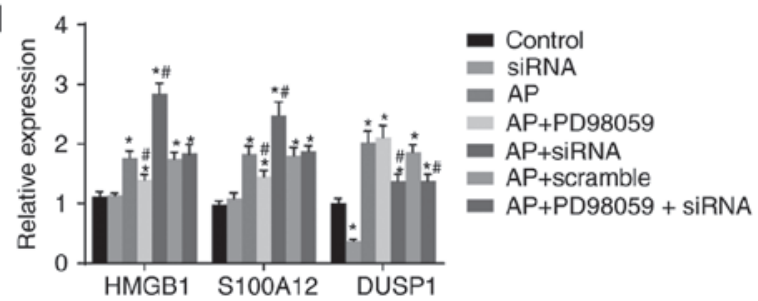

Figure 4. mRNA expression of proinflammatory cytokines (TNF- $\alpha$, IL-1 $\beta$ and IL-6), DUSP1, HMGB1 and S100A12 in the pancreas, liver, kidney and lung tissues of mice in each group detected using reverse transcription-quantitative polymerase chain reaction analysis. (A) mRNA expression of TNF- $\alpha$, IL-1 $\beta$ and IL-6 in pancreatic tissues of mice in each group; (B) mRNA expression of DUSP1, HMGB1 and S100A12 in pancreatic tissues of mice in each group; (C) mRNA expression of TNF- $\alpha$, IL-1 $\beta$ and IL-6 in liver tissues of mice in each group; (D) mRNA expression of DUSP1, HMGB1 and S100A12 in liver tissues of mice in each group; (E) mRNA expression of TNF- $\alpha$, IL-1 $\beta$ and IL-6 in kidney tissues of mice in each group; (F) mRNA expression of DUSP1, HMGB1 and S100A12 in kidney tissues of mice in each group; (G) mRNA expression of TNF- $\alpha$, IL-1 $\beta$ and IL-6 in lung tissues of mice in each group; (H) mRNA expression of DUSP1, HMGB1 and S100A12 in lung tissues of mice in each group; $\mathrm{P}<0.05$, compared with the control group; ${ }^{\#} \mathrm{P}<0.05$, compared with the AP group. RT-qPCR, reverse transcription-quantitative polymerase chain reaction; DUSP1, dual-specificity phosphatase-1; TNF- $\alpha$, tumor necrosis factor- $\alpha$; IL-6, interleukin-6; IL-1 $\beta$, interleukin-1 $\beta$; HMGB1, high mobility group box-1; AP, acute pancreatitis; siRNA, small interfering RNA.

exhibited the most marked reduction $(\mathrm{P}<0.05)$, whereas no significant change in the expression of DUSP1 was observed. The AP+siRNA group had significantly increased expression levels of p-ERK, p-JNK and p-p38 in the pancreatic, liver, kidney and lung tissues, among which the pancreatic tissue exhibited the most marked increase, whereas the expression of DUSP1 was decreased $(\mathrm{P}<0.05)$. In the AP+PD98059+siRNA group, no significant differences in the expression levels of p-ERK, p-JNK or p-p38 were observed in the pancreatic, liver, kidney and lung tissues ( $\mathrm{P}>0.05)$, however, the expression of DUSP1 was decreased $(\mathrm{P}<0.05)$.

\section{Discussion}

AP is known as a common inflammatory disease and the incidence of adult AP has increased in recent decades $(4,22)$. Previous studies have demonstrated that MAPKs are important in AP and that the DUSP1 gene is involved in the acute inflammatory response $(23,24)$. In the present study, the role of
DUSP1 gene silencing on the release of proinflammatory cytokines through regulation of the MAPK signaling pathway was investigated in AP mice. The experimental results indicated that DUSP1 gene silencing promoted the release of proinflammatory cytokines through activation of the MAPK signaling pathway in mice with AP.

Initially, the AP mice exhibited increased serum levels of TNF- $\alpha$, IL-1 $\beta$, IL-6, HMGB1, S100A12 and amylase, and mice in the AP+siRNA group had higher expression levels of these factors. TNF- $\alpha$, IL-1 and IL-6, as proinflammatory cytokines, are key regulators of acute inflammation and are important in the pathogenesis of inflammatory diseases $(25,26)$. HMGB1 and S100A12, as mediators of inflammation, are considered to contribute to the proinflammatory response in acute respiratory distress syndrome (27). The results of a study performed by Xiang et al also demonstrated that there were increased serum levels of HMGB1, TNF- $\alpha$ and IL- 6 in traumatic pancreatitis (28). Serum amylase is widely used as a biochemical marker of pancreatic inflammation (29). A 

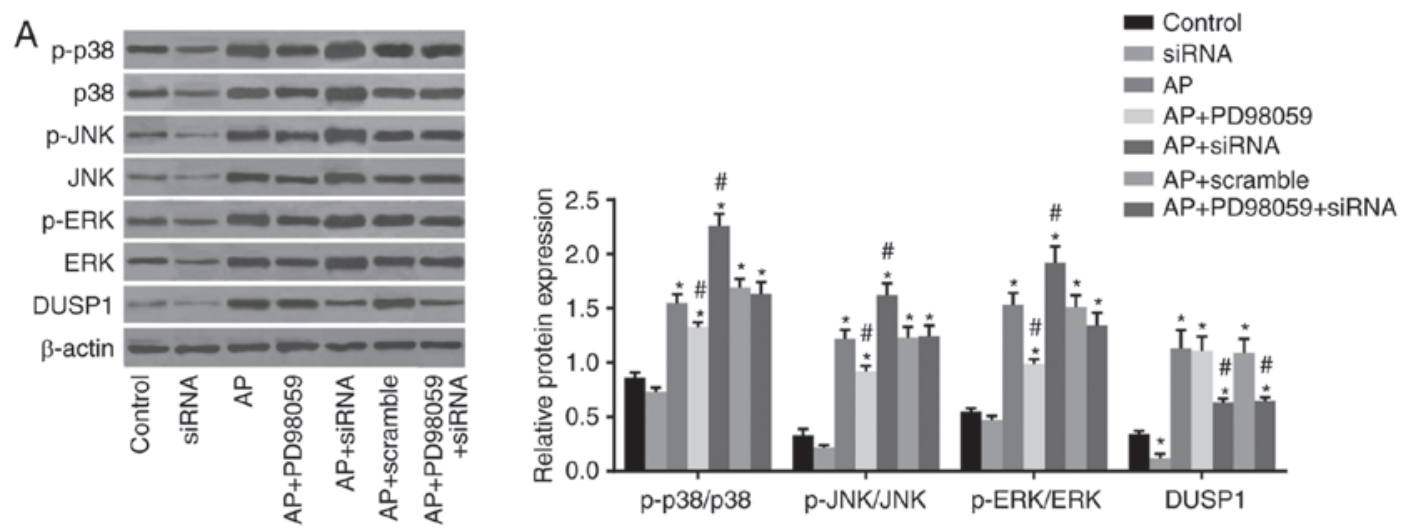

B
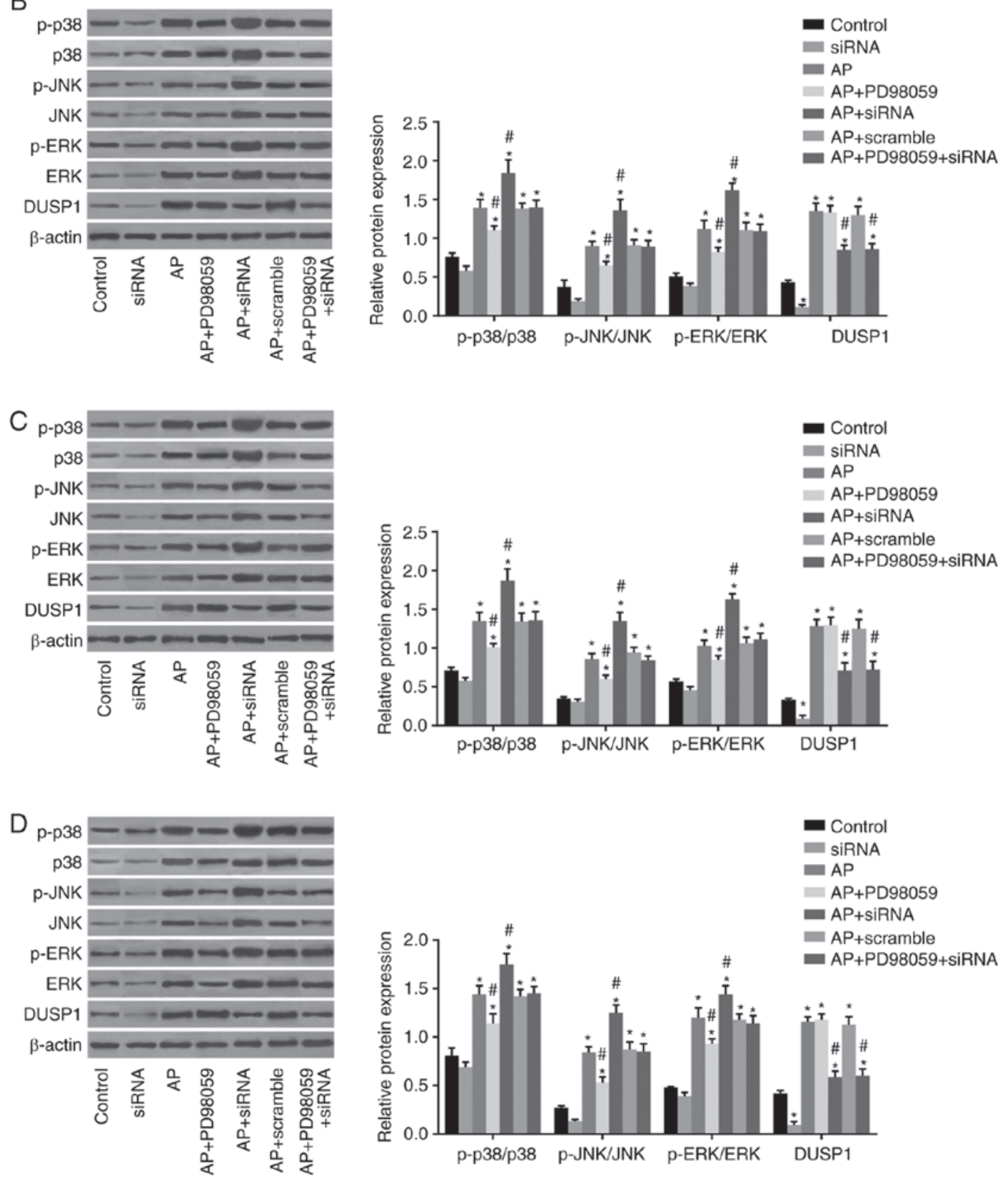

Figure 5. Expression of DUSP1 and MAPK pathway-related genes (p-ERK, p-JNK and p-p38) in pancreatic, liver, kidney and lung tissues of mice in each group detected using western blot analysis. (A) Electrophoresis band chart and histogram for expression of DUSP1 and MAPK pathway-related proteins in pancreatic tissues of mice in each group. (B) Electrophoresis band chart and histogram for expression of DUSP1 and MAPK pathway-related proteins in liver tissues of mice in each group; (C) electrophoresis band chart and histogram for expression of DUSP1 and MAPK pathway-related proteins in kidney tissues of mice in each group; (D) electrophoresis band chart and histogram for expression of DUSP1 and MAPK pathway-related proteins in lung tissues of mice in each group; ${ }^{*} \mathrm{P}<0.05$, compared with the control group; ${ }^{*} \mathrm{P}<0.05$, compared with the AP group. DUSP1, dual-specificity phosphatase-1; AP, acute pancreatitis; siRNA, small interfering RNA; MAPK, mitogen-activated protein kinase; ERK, extracellular signal-regulated kinase; JNK, c-Jun N-terminal kinase; p-, phosphorylated. 
previous study indicated that serum amylase is always high in AP (30). Matas-Cobos reported increased serum amylase levels in AP, which was consistent with the present study (31). Therefore, the results indicated that DUSP1 gene silencing upregulated the expression of proinflammatory cytokines, HMGB1, S100A12 and amylase.

The AP mice also had significantly increased mRNA expression levels of TNF- $\alpha$, IL-1 $\beta$, IL- 6 , HMGB1 and S100A12 in pancreatic, liver, kidney and lung tissues, among which pancreatic tissues exhibited the most marked changes. The expression levels of these factors were increased in the AP+siRNA group, but decreased in the AP+PD98059 group. PD98059, serving as an inhibitor of the MAPK signaling pathway, can inhibit the activation of MAPK kinase 1, phosphorylation of ERK and expression of MAPK proteins (32). A previous study identified that the activation of MAPK is associated with the upregulation of gene expression involved in the proliferation and apoptosis of pancreatic cancer cells (33). The p38 MAPK signaling pathway can function as a regulator of the inflammatory response, and inhibition of the p38 MAPK signaling pathway can alleviate experimental AP in mice (34). A study by Sun et al also demonstrated that inhibition of the MAPK signaling pathway decreased the mRNA expression of proinflammatory cytokines (35). A previous study by Wang et al identified increased mRNA expression levels of TNF- $\alpha$, IL- $1 \beta$ and IL- 6 in lung and pancreatic tissues $(36,37)$. The results suggested that inhibition of the MAPK signaling pathway downregulated the mRNA expression of proinflammatory cytokines, HMGB1 and S100A12 in AP mice, whereas silencing the DUSP1 gene upregulated their expression levels.

Finally, the AP mice exhibited increased expression levels of p-ERK, p-JNK and p-p38 in pancreatic, liver, kidney and lung tissues, among which the pancreatic tissue exhibited the most marked changes; the expression of these factors was increased in the AP+siRNA group, but decreased in the AP+PD98059 group. It is known that p38 MAPK, p-ERK, p-JNK, p-p38 and p54/p46 are members of the MAPK family (38). ERK and p38 are key in the overproduction of exocrine pancreatic cytokines (39). DUSPs are involved in regulating the phosphorylation of Erk1/2, p38 and JNK1/2 (40). It has been demonstrated that the phosphorylation of ERK and p38 is regulated by DUSP1 (41). A previous study by Zhang et al also reported the upregulation of downstream signaling molecules, p-ERK, p-JNK and p-p38, mediated by the inhibition of DUSP1 (42). These results indicated that DUSP1 gene silencing increased the expression levels of p-ERK, p-JNK and p-p38.

In conclusion, the data obtained in the present study indicated that silencing the DUSP1 gene using lentiviral vector-mediated siRNA promoted the release of proinflammatory cytokines via activation of the MAPK signaling pathway in AP mice, which aggravated AP. Several factors affect the DUSP1 and MAPK signaling pathway; therefore, further investigations are required to identify effective therapeutic regimens for patients with AP in the future.

\section{Acknowledgements}

The present study was supported by the Shandong Provincial Medical Science and Technology Development Project (grant no. 2016WS0198).

\section{Competing interests}

The authors declare that they have no competing interests.

\section{References}

1. Munsell MA and Buscaglia JM: Acute pancreatitis. J Hosp Med 5: 241-250, 2010

2. Liu B, Huang J and Zhang B: Nobiletin protects against murine l-arginine-induced acute pancreatitis in association with downregulating p38MAPK and AKT. Biomed Pharmacother 81: 104-110, 2016.

3. Wittau M, Mayer B, Scheele J, Henne-Bruns D, Dellinger EP and Isenmann R: Systematic review and meta-analysis of antibiotic prophylaxis in severe acute pancreatitis. Scand J Gastroenterol 46: 261-270, 2011.

4. Kylänpää ML, Repo H and Puolakkainen PA: Inflammation and immunosuppression in severe acute pancreatitis. World J Gastroenterol 16: 2867-2872, 2010.

5. Tonsi AF, Bacchion M, Crippa S, Malleo G and Bassi C: Acute pancreatitis at the beginning of the 21st century: The state of the art. World J Gastroenterol 15: 2945-2959, 2009.

6. Zerem E: Treatment of severe acute pancreatitis and its complications. World J Gastroenterol 20: 13879-13892, 2014

7. Bradley EL III and Dexter ND: Management of severe acute pancreatitis: A surgical odyssey. Ann Surg 251: 6-17, 2010.

8. Moncho-Amor V, Ibañez de Cáceres I, Bandres E, Martínez-Poveda B, Orgaz JL, Sánchez-Pérez I, Zazo S, Rovira A, Albanell J, Jiménez B, et al: DUSP1/MKP1 promotes angiogenesis, invasion and metastasis in non-small-cell lung cancer. Oncogene 30: 668-678, 2011.

9. Horita H, Wada K, Rivas MV, Hara E and Jarvis ED: The dusp1 immediate early gene is regulated by natural stimuli predominantly in sensory input neurons. J Comp Neurol 518: 2873-2901, 2010.

10. Liu F, Gore AJ, Wilson JL and Korc M: DUSP1 is a novel target for enhancing pancreatic cancer cell sensitivity to gemcitabine. PLoS One 9: e84982, 2014.

11. Zhang X, Hyer JM, Yu H, D'Silva NJ and Kirkwood KL: DUSP1 phosphatase regulates the proinflammatory milieu in head and neck squamous cell carcinoma. Cancer Res 74: 7191-7197, 2014.

12. Dauletbaev N, Herscovitch K, Das M, Chen H, Bernier J, Matouk E, Bérubé J, Rousseau S and Lands LC: Down-regulation of IL-8 by high-dose vitamin D is specific to hyperinflammatory macrophages and involves mechanisms beyond up-regulation of DUSP1. Br J Pharmacol 172: 4757-4771, 2015.

13. Sun X, Liu C, Qian M, Zhao Z and Guo J: Ceramide from sphingomyelin hydrolysis differentially mediates mitogen-activated protein kinases (MAPKs) activation following cerebral ischemia in rat hippocampal CA1 subregion. J Biomed Res 24: 132-137, 2010.

14. Cargnello $M$ and Roux PP: Activation and function of the MAPKs and their substrates, the MAPK-activated protein kinases. Microbiol Mol Biol Rev 75: 50-83, 2011.

15. Qin Z, Dai L, Defee M, Findlay VJ, Watson DK, Toole BP, Cameron J, Peruzzi F, Kirkwood K and Parsons C: Kaposi's sarcoma-associated herpesvirus suppression of DUSP1 facilitates cellular pathogenesis following de novo infection. J Virol 87: 621-635, 2013.

16. Sandoval J, Escobar J, Pereda J, Sacilotto N, Rodriguez JL, Sabater L, Aparisi L, Franco L, Lopez-Rodas G and Sastre J: Pentoxifylline prevents loss of PP2A phosphatase activity and recruitment of histone acetyltransferases to proinflammatory genes in acute pancreatitis. J Pharmacol Exp Ther 331: 609-617, 2009.

17. Singer $\mathrm{O}$ and Verma IM: Applications of lentiviral vectors for shRNA delivery and transgenesis. Curr Gene Ther 8: 483-488, 2008.

18. Giry-Laterrière $M$, Verhoeyen $\mathrm{E}$ and Salmon P: Lentiviral vectors. Methods Mol Biol 737: 183-209, 2011.

19. Schaible HG, von Banchet GS, Boettger MK, Bräuer R, Gajda M, Richter F, Hensellek S, Brenn D and Natura G: The role of proinflammatory cytokines in the generation and maintenance of joint pain. Ann N Y Acad Sci 1193: 60-69, 2010.

20. Jiang QL, Wang JM, Jiang S, Wen LM and Zhou H: Large-scale real-time titration of green-fluorescence-protein-marked recombinant retrovirus: Comparison with standard titration method. Di Yi Jun Yi Da Xue Xue Bao 23: 1101-1103, 2003 (In Chinese). 
21. Livak KJ and Schmittgen TD: Analysis of relative gene expression data using real-time quantitative PCR and the $2^{-\Delta \Delta C_{\mathrm{T}}}$ method. Methods 25: 402-408, 2001.

22. Morinville VD, Barmada MM and Lowe ME: Increasing incidence of acute pancreatitis at an American pediatric tertiary care center: Is greater awareness among physicians responsible? Pancreas 39: 5-8, 2010.

23. Alaoui-Jamali M: Comment on 'p38 MAPK inhibition alleviates experimental acute pancreatitis in mice'. Hepatobiliary Pancreat Dis Int 14: 330, 2015.

24. Korhonen R, Turpeinen T, Taimi V, Nieminen R, Goulas A and Moilanen E: Attenuation of the acute inflammatory response by dual specificity phosphatase 1 by inhibition of p38 MAP kinase. Mol Immunol 48: 2059-2068, 2011.

25. Dimitrakova E and Kostov I: Studies on the level of proinflammatory cytokines IIL-1a, IL-1b, IL-6, TNF-a in pregnant women with acute pyelonephritis. Akush Ginekol 50: 3-6, 2011 (In Bulgarian)

26. Jang $\mathrm{CH}$, Choi JH, Byun MS and Jue DM: Chloroquine inhibits production of TNF-alpha, IL-1beta and IL- 6 from lipopolysaccharide-stimulated human monocytes/macrophages by different modes. Rheumatology 45: 703-710, 2006.

27. Müller MC, Tuinman PR, Vlaar AP, Tuip AM, Maijoor K, Achouiti A, Van t Veer C, Vroom MB and Juffermans NP: Contribution of damage-associated molecular patterns to transfusion-related acute lung injury in cardiac surgery. Blood Transfus 12: 368-375, 2014

28. Xiang K, Cheng L, Luo Z, Ren J, Tian F, Tang L, Chen T and Dai R: Glycyrrhizin suppresses the expressions of HMGB1 and relieves the severity of traumatic pancreatitis in rats. PLoS One 9: e115982, 2014

29. Hofmeyr S, Meyer C and Warren BL: Serum lipase should be the laboratory test of choice for suspected acute pancreatitis. S Afr J Surg 52: 72-75, 2014.

30. Ghimire R, Thapa AS, Karki D and Shrestha DK: Routine measurement of serum amylase in acute abdomen. JNMA J Nepal Med Assoc 52: 982-985, 2014.

31. Matas-Cobos AM, Redondo-Cerezo E, Alegría-Motte C, Martínez-Chamorro A, Saenz-López P, Jiménez P, Jiménez MR, González-Calvín JL, de Teresa J and Osuna FR: The role of Toll-like receptor polymorphisms in acute pancreatitis occurrence and severity. Pancreas 44: 429-433, 2015.

32. Di Paola R, Galuppo M, Mazzon E, Paterniti I, Bramanti P and Cuzzocrea S: PD98059, a specific MAP kinase inhibitor, attenuates multiple organ dysfunction syndrome/failure (MODS) induced by zymosan in mice. Pharmacol Res 61: 175-187, 2010.
33. Furukawa T, Tanji E, Kuboki Y, Hatori T, Yamamoto M, Shimizu K, Shibata N and Shiratori K: Targeting of MAPK-associated molecules identifies SON as a prime target to attenuate the proliferation and tumorigenicity of pancreatic cancer cells. Mol Cancer 11: 88, 2012.

34. Cao MH, Xu J, Cai HD, Lv ZW, Feng YJ, Li K, Chen CQ and Li YY: p38 MAPK inhibition alleviates experimental acute pancreatitis in mice. Hepatobiliary Pancreat Dis Int 14: 101-106, 2015.

35. Sun HY, Hu KZ and Yin ZS: Inhibition of the p38-MAPK signaling pathway suppresses the apoptosis and expression of proinflammatory cytokines in human osteoarthritis chondrocytes. Cytokine 90: 135-143, 2017.

36. Wang HT, Fang YQ, Bao XC, Yuan HR, Ma J, Wang FF, Zhang S and Li KC: Expression changes of TNF- $\alpha$, IL-1 $\beta$ and IL- 6 in the rat lung of decompression sickness induced by fast buoyancy ascent escape. Undersea Hyperb Med 42: 23-31, 2015.

37. Wang XY, Tang QQ, Zhang JL, Fang MY and Li YX: Effect of SB203580 on pathologic change of pancreatic tissue and expression of TNF- $\alpha$ and IL-1 $\beta$ in rats with severe acute pancreatitis. Eur Rev Med Pharmacol Sci 18: 338-343, 2014.

38. Costa AP, Lopes MW, Rieger DK, Barbosa SG, Gonçalves FM, Xikota JC, Walz R and Leal RB: Differential activation of mitogen-activated protein kinases, ERK 1/2, p38 ${ }^{\mathrm{MAPK}}$ and JNK p54/p46 during postnatal development of rat hippocampus. Neurochem Res 41: 1160-1169, 2016.

39. Samuel I, Zaheer A and Fisher RA: In vitro evidence for role of ERK, p38, and JNK in exocrine pancreatic cytokine production. J Gastrointest Surg 10: 1376-1383, 2006.

40. Wang Z, Reinach PS, Zhang F, Vellonen KS, Urtti A, Turner H and Wolosin JM: DUSP5 and DUSP6 modulate corneal epithelial cell proliferation. Mol Vis 16: 1696-1704, 2010.

41. Leyva-Ilades D, Cherla RP, Lee MS and Tesh VL: Regulation of cytokine and chemokine expression by the ribotoxic stress response elicited by Shiga toxin type 1 in human macrophage-like THP-1 cells. Infect Immun 80: 2109-2120, 2012.

42. Zhang Q, Yu J, Wang J, Ding CP, Han SP, Zeng XY and Wang JY: The red nucleus TNF- $\alpha$ participates in the initiation and maintenance of neuropathic pain through different signaling pathways. Neurochem Res 40: 1360-1371, 2015. 